\title{
Reimagining Peter Pan: The Postmodern Childhood Portrayal in Wendy (2020)
}

\author{
Dhita Hapsarani ${ }^{1}$, Nadia Farah Lutfiputri ${ }^{2}$ \\ Universitas Indonesia, INDONESIA \\ e-mail: dhitahapsarani@gmail.com¹; nadia.lutfiputri@gmail.com²
}

\begin{abstract}
The notion and society's view towards childhood remain to change over time and vary between different cultures and social backgrounds. Literary works, such as films or novels from different periods that feature children's characters, can be the suitable medium to identify the shifts and differences. This article analyzes the film Wendy (2020) as the latest adaptation of J.M. Barrie's classic children's novel Peter Pan (1911). The film has made some transformations from the original novel to make the story more relevant in today's context, including showcasing a different kind of childhood from Barrie's novel. Using textual and comparative analysis, this study attempts to see how the transformations in the film adaptation displays a postmodern childhood construction. Referring to the concept of postmodern childhood, Linda Hutcheon's adaptation theory, and Bordwell and Thompson's elements of film analysis, this study reveals how Wendy (2020) has exemplified postmodern childhood through the portrayal of children's roles, children's agency, and children-adults relationship.
\end{abstract}

Keywords: Childhood construction; children's literature; film adaptation; Peter Pan; postmodern childhood.

\section{INTRODUCTION}

The way we perceive childhood remains to change over time. The study and development of the concept of childhood started to rise when Philippe Ariès (1960) published The Centuries of Childhood. In Meynert's (2013) review on the history of childhood, Ariès is said to:

construct[s] a progression from 'no conception of childhood to coddling in the 13th century, and then to the moralistic period in the 16th century, in which childhood was seen as a time for discipline and preparation for adulthood (p.80).

According to Aries, childhood is historically constructed, and the idea is subject to change, which this article aims to see. During the medieval era in Europe up to the $17^{\text {th }}$ century, the idea of childhood did not exist and children were more seen as miniature adults. The modern concept of childhood, which sees childhood as a completely different stage of life from adulthood, started to form in the 19th century as industrialization began in Europe. Some characteristics of modern childhood are that children need to be safe and protected, dependent on adults, and often viewed as innocent human beings. These characteristics are also reflected in literary works that were published in that era. The postmodern concept of childhood, which challenges the regularity and universality of modern childhood characteristics, began to develop in the late 20th century in Europe and North America. It was powered by World War II and the invention of electronic media that also leads to the shift of family structure in the post-industrialist society (Mook, 2007, p.145).

At the end of the 20th century, literary works like novels, films, and television series began to portray the idea of postmodern childhood, a term used by Bignell (2005), Chappell (2008), and Kincheloe (2018). The first example is the Home Alone series, which has five films from 1990 to 2012. The plot of each film revolves around children who find themselves left alone by their family during the holiday season and face challenges posed by criminals. In the films, the main character is portrayed as an independent child who manages to take care of himself with no adult figures (Kincheloe, 2011, p.281). The Harry Potter series, as another example, is also claimed by Chappell (2008) as novels and films which show that instead of just accepting the binaries concept mostly appeared in modern literature, postmodern children are now having more agency and resistance, as well as facing ambiguity and complexity since they were young (p.292). Since they were children, Harry and his friends were shown to question injustice in the wizarding world and take the initiative 
to solve many problems instead of passively waiting for the adult wizards to do something. There was also Teletubbies, a children's television program which aired from 1997 to 2001. It is about four creatures with short limbs, large heads, antennas, and colored skin. Bignell (2005) concluded that this program had demonstrated postmodern childhood's perspective through its ambiguous portrayal of the characters who appeared ambiguous with their childlike-adult aliens. The childhood that the child protagonists in these examples experience is different from the childhood portrayed in the modernist literary works, where children live in the world like machines with the straightforward notion of right and wrong or good and evil and have to conform to the existing structure (Chappell, 2008, p.282).

Another film that was released recently and explored the theme of childhood is Wendy (2020). It is a film directed by Benh Zeitlin from a screenplay written by Benh and Eliza Zeitlin. The film tells about Wendy Darling, a little girl from a working-class family living in the Southern United States with her single mother and her twin brothers, James and Douglas. She lives in a rundown home over a diner owned by her mother. Afraid to grow up and have to live the way her mother lives, one night Wendy and her brothers decide to jump from their house roof to a moving train. They end up meeting Peter Pan, a young boy who takes them to a mysterious volcanic island, and on that island, they have an adventure together.

Wendy (2020) is the latest adaptation of J.M. Barrie's Peter Pan story, which was introduced as a fantasy play in 1904. Seven years later, in 1911, this play was published as a novel titled Peter Pan and Wendy and later republished under the title of Peter Pan. For more than a century, the story of Peter Pan, the never-growup boy living in Neverland, remains popular, especially among children that it has been adapted into different media, such as films and TV series. Some of them are Disney's animated Peter Pan (1953), Hook (1991), and Pan (2003). Several researches have explored the theme of childhood in the novel Peter Pan (1911), including the research by Le Roux (2016) and Yoo (2019). In their research, both stated that this novel portrays childhood in an imaginary innocent way or showing the children's purity, simplicity, and lack of knowledge assumed by adults. This kind of portrayal puts children more as objects of adult desires to fulfil their sense of nostalgia for a lost childhood.

However, this childhood portrayal seems appear differently in Wendy (2020). Unlike the original work that is a fantasy story, Wendy (2020) blends the elements of realism and fantasy. The story exists in realistic settings but with a touch of fantasy elements. There are significant changes in the narrative elements, such as the settings and the character's social background. For instance, the child protagonists in Wendy (2020) are depicted as coming from the lower-class society. The director, Benh Zeitlin, admitted that he wanted to bring the fantasy story within realistic settings as he thought that the children's adventure in Peter Pan could not be happening in a real-life setting. (Hicks, 2020). Therefore, he tried to remake the story with "a sense of real plausibility and accessibility" to make it more relatable to children of the 21st century from different social backgrounds. Each work reflects the society of their own time, thus using the social context and childhood perception from the early twentieth century for a twenty-first-century film might not be relevant anymore. Zeitlin's perspective on childhood that is showcased in the film might now fit with the postmodern view of childhood.

Several studies have contributed to the discussion of how postmodern childhood is portrayed in literature by pointing out the postmodern childhood's characteristics and the relationship between children and adults. In comparison to modern childhood, Kincheloe (2011), Loo (2012), and Meynert (2013) noted that the postmodern childhood is usually portrayed as less innocent, more mature, and more independent. Chappell (2008, p.282), who analyzed postmodern childhood in the Harry Potter series, also mentioned that postmodern children have become more critical in questioning the power structure and roles given to them in society. As for the child-adult relationship, both Kincheloe (p.281) and Loo (p.59) stated that the line between childhood and adulthood is slowly blurred. Children are now more exposed to issues that used to be considered appropriate for adults, such as violence and business-related ideas.

Based on these findings, this article will further analyze the change which occurs in Wendy (2020) that is adapted from Peter Pan (1911) and explores the postmodern childhood in Wendy (2020) by examining how the children's characteristics and the child-adult relationships are being portrayed. Previously, there has been no research which discuss the shift on the childhood portrayal that is showcased in the film, and thus it is worth to explore further. Based on my preliminary research, the change shown in Wendy reflects a different childhood construction from the one in the source novel, Peter Pan (1911), and it is now exemplifying the concept of postmodern childhood. Children are depicted to have more agency, more mature, and are not portrayed merely as the objects of nostalgia for adults. 


\section{METHOD}

This article will explore the transformation from Peter Pan (1911) to Wendy (2020) to see how it portrays postmodern childhood. The study uses textual analysis and adaptation methods. First, Hutcheon's (2006) theory on adaptations will be used to examine the changes in the narrative elements in Wendy to see how the transformations suggest different childhood constructions from the source novel. McCallum (2018, p. 1) stated that film and television adaptations of literary texts play an important role in transferring or reshaping the concept of childhood and youth previously shown in the original work.

The next step is to analyze the narrative and film's cinematographic aspects of selected scenes by implementing Bordwell and Thompson's (2008) film elements. This step allows me to identify postmodern childhood characteristics (i.e., children's roles, agency, and the child-adult relationship) portrayed in the movie.

According to Lyotard (1984), postmodernism, as the antithesis of modernism, is a concept which "critically challenges the certainty of objective truths, the relevance of universal or metanarratives, and language as representative of truth" (as cited in Meynert, 2013, p.18). Concerning childhood, postmodern childhood studies attempt to challenge the concept of modern childhood, in which society puts children in a dichotomous hierarchical relationship with adults and has a specific idea on the kind of roles children should play in their childhood. This view is considered limited to children from particular social and family structures. Postmodern childhood studies scholars believe in the plurality of childhood across and within cultures and the child's active agency. In Meynert's view, a child in the postmodern world is dynamic, competent, transcends multiple identities and cultures, and has a fluid relationship with adults and other children (2013, p.104).

This theory of childhood construction can also be implemented in literary analysis as the childhood portrayal may reflect current views of childhood in society.

\section{RESULTS \& DISCUSSIONS}

\section{The transformations from Peter Pan (1911) to Wendy (2020)}

Wendy (2020) departs from Peter Pan's story, which J.M. Barrie originally wrote as a play in 1904 and then published as a novel titled Peter Pan and Wendy in
1911. Later on, the text has been republished many times under the title Peter Pan. This novel tells the story of Wendy, John, and Michael Darling, who lives with their parents and a nanny dog named Nana in London, England. One night, when Mr. and Mrs. Darling and also Nana are not there, Peter Pan and the fairy named Tinker Bell unexpectedly come into their nursery room through the window. Peter Pan, the boy who never grows up, then convinces the children to fly and have an adventure together with him in a magical island called Neverland. They finally agree and have some adventures together in Neverland, such as interacting with mermaids and fighting the pirates under Captain Hook's lead.

Like its original story, Wendy (2020) explores the theme of children's adventure and growing up as the center of the narrative. Wendy is a 10 -year-old girl who lives with her single mother and twin brothers, James and Douglas, over a small drab diner owned and run by her mother. The diner is close to railway lines in the southern part of the United States. From early age, the children work there to help their mother, and they were expected to get working-class jobs in their future. Wendy and her brothers do not want to grow up because they are afraid that they have to give up on their dreams and are forced by the circumstances and society to end up like their mother. Therefore, one day the Darling children escape their home and follow a boy, who later is known as Peter Pan, to a volcanic island that he considers the land of freedom.

On that island, other children who also escape their home or do not have a family can gain freedom and do whatever they want without being interrupted by adults. Furthermore, even though the island is located in a real-life setting that can be reached by train and boat, it is a magical island because real-world time does not work there. Children will stay young as long as their minds are filled with happy memories and believe in the spirit of a glowing sea creature called Mother that will protect them. However, once sadness enters and they no longer have any dream or believe in Mother, they will immediately become old. The problem starts when Douglas is missing, and James becomes sad. As the rule states, James turns into an older man in only a few days, signified by his wrinkled skin and his long white beard and hair. He then gathers with the other old people and makes a plan to capture 'Mother,' who they believe can make them young again. Knowing this plan, Wendy, Peter Pan, and other children do not stay still and try to stop their efforts.

The film Wendy (2020) is a work of adaptation of J.M. Barrie's Peter Pan (Edelstein, 2020). As Hutcheon (2006) stated, adaptations is its own palimpsestic thing 
or stories that have changed over time. They are repetitions of a familiar story, but not a replication. Looking at this understanding, in Wendy, some elements are indeed maintained from the original story, which creates a sense of familiarity. However, some parts and elements are transformed and interpreted in a new way. The central plot of Wendy is quite similar to Peter Pan, as it tells the story of children who cherish their childhood moments and refuse to grow up. Some original work characters are also still there, like Peter Pan, Wendy, and the Lost Boys. However, other than those things, many aspects are being changed. In this article, some transformations that will be analyzed deeper are the settings of place and time, the Darling family's social background, Neverland, and Peter Pan.

\section{The Setting of Place and Time}

The first noticeable thing that makes Peter Pan (1911) and Wendy (2020) different is the setting of the story. The Darling family in Peter Pan is a British family living in London, England in the early 20th century. Meanwhile, the Darling family in Wendy is an American family who lives in a small unspecified town. The situation portrayed in the film indicates that the story takes place in the present times. The change in the setting of time and place indicates that Wendy is intended to bring the classic tale to be more relatable to the contemporary society of the 21 st century. As Hutcheon argued, "the change of the national setting or the time of the story may lead to a major change in how ideologically and artistically the adapted plot has been interpreted" (2006, p. 28).

\section{The Darling Family Background}

Another thing that is appeared differently between the novel and the film is the Darling family's social background. In Peter Pan, the Darlings is portrayed as an English middle-class family living in the big city. The family, which consists of Mr. George Darling, Mrs. Mary Darling, and three children named Wendy, John, and Michael, reflects the concept of the modern nuclear family. The concept of a nuclear family began to establish and rise in the $19^{\text {th }}$ century in Western Europe. Some characteristics of the modern nuclear family are that they create boundaries between the world of adults or parents and children, have clear roles and functions for each family member, and value togetherness above individuals (Mook, 2007, p. 141). A father usually goes to work, and a mother stays at home to do domestic work and takes care of children. Meanwhile, children are not given any specific role during their childhood phase, except they need to get an education and are protected by adults in the family. Some families even have a nurse or tutor to take care of the children specifically. This family structure can be seen in the Darling family with Mr. George Darling described as a bank clerk and Mrs. Mary Darling a housewife. They also have a Newfoundland dog called Nana, who accompanies the children when they go to school or stay in the house's nursery room.

In contrast with the Darling family in Peter Pan, the Darlings in Wendy consists of a single mother and three children named James, Douglas, and Wendy. There is no clear indication whether their father had passed away or if their parents were divorced or never actually got married. No one in the family ever mentions the father. Unlike the original story, Wendy in the film is the youngest child, and James and Douglas are twins. This family is portrayed as coming from a lower-class family living in a small town. Wendy's mother is the owner of a diner, where she regularly serves the customers directly, and the children are also given responsibilities to work in that diner. This family background reflects the family structure commonly found in the United States today, where the number of children raised by a single mother is rising. As of 2017, about $21 \%$ of U.S. children live only with a single mother, and about $30 \%$ of those single mothers live below the poverty line (Pew Research Center, 2017). With this background, some children, just like in the film, are then expected to face this social problem and help their families since they are young.

\section{Neverland and Peter Pan}

From London, Peter Pan and the Darling children in Peter Pan (1911) fly to Neverland. At the beginning of the novel, Neverland is an imaginary colorful, magical island in a child's mind. Later it is also explained that what is inside Neverland might vary for each person. For example, "John's, for instance, had a lagoon with flamingos flying over it at which John was shooting, while Michael, who was very small, had a flamingo with lagoons flying over it"(Barrie, p.14). From the description, the readers might think that Neverland is not a real place. However, this expectation changes when Peter Pan comes to the Darlings and convinces them that Neverland is a real place far away from London. The way to reach Neverland is by using the imagination as children and flying following Peter Pan's direction "Second to the right, and straight on till morning." Neverland is a place where Peter Pan and the Lost Boys live. Peter Pan described the Lost Boys as boys "who fall out of their perambulators when the nurse is looking the other way. If they are not claimed in seven days, they are sent far away to the Neverland to defray expenses." (Barrie, p.44). Other than these boys, it is also a home for a group of pirates led by Captain Hook, the Indians tribe, and mythical creatures 
like fairies and mermaids. Barrie's creation of Neverland with many fantasy elements shows that the author positions it as the children's utopian sanctuary, where children can escape the struggle of adulthood and get eternal childhood (Franklin, 2012). On that island, the children are free to do anything they wish with no restrictions and rules they encounter in real life, which puts childhood farther away from adulthood and reality. Peter Pan himself is first introduced as an imaginative character that visits children in their dreams. As the symbol of youth eternity he never grows up. The physical appearance of Peter Pan in the novel is not described, except that he is lovely, clad in skeleton leaves and the juices that ooze out of trees, and has all his first teeth. Other than that, he also has the remarkable ability to fly.

In Wendy, the colorful fantasy of Neverland is replaced by a tropical volcanic island in a real-life setting that can be reached by train and boat. There are no magical creatures like fairies and mermaids anymore, except a glowing sea creature called Mother. As for Peter Pan, he appears as a black-skinned young boy who, throughout the film, wears a school uniform. Here, he is still portrayed as a boy who refuses to grow up and is abandoned by his family. However, he cannot fly. Other than Peter Pan, the other inhabitants on the island are the lost boys described as boys who do not have a family or escape from their home and older people trapped in there. The children and the older people are depicted living in different parts of the island. Children mostly spend their time in the part dominated by natural green forest, where they can have fun running and playing around in nature, without being interrupted by adults. Meanwhile, the older people's place is a destructive, dusty, and dry land due to the environmental crisis. There is one scene that captures this contrast. It happens when Wendy wakes up from sleeping on a tree and finds an older adult there. Getting discovered by Wendy, that older adult immediately runs to escape. However, Wendy follows him until the older man steps out of the forest, and the scenery changes drastically into a vast dry land. Wendy stops her step, and the camera shoots Wendy standing in the middle between the dry grey land on the front and the green forest on her back. (Zeitlin, 2020, 43:36 - 44:05).

This island has one sign which differentiates it from the real world. On that island, real-world time does not exist. Children will remain young as long as there are only happy memories in their minds and keep playing around freely. However, when sadness enters their mind, they will turn old immediately. Despite its rule, which is intended to portray the island as a special island for children separated from reality, the distinction is vague. The color tone used to depict the island is just the same as portraying the children's home. From the beginning until the end, the film is dominated by low saturated earth tone color, which creates a sense of naturalness and murkiness. From this depiction, the island's existence in Wendy is not necessarily the same as Neverland in Peter Pan. If Neverland serves as an imaginary fantasy island for children to escape reality, the island in Wendy is the extension of reality itself with social issues and problems children have to face.

\section{The Postmodern Childhood in Wendy (2020)}

Another new interpretation that occurs in Wendy (2020) is how this film depicts childhood. Although this film still focuses on the child figures, the lives of the children are portrayed differently The dominant childhood imagery in Western society during the modern era and previously shown in Peter Pan (1911) does not appear anymore. Instead, the childhood portrayal is being changed into the concept of postmodern childhood, which can be seen through how this film presents the children's roles, children's agency, and children-adults relationship. Postmodern childhood studies aim to challenge the universality that the modern view of childhood holds, rejects child-adult dualism, and constitutes new possibilities for children (Meynert, 2013, p.109).

\section{Children's Roles}

Looking at the children's roles during their childhood in Wendy, the family's social background and structure must be considered. In postmodern society, family structures become more diverse, affecting how children perceive and experience their childhood. One aspect that contributes to this point of view is the awareness that not all children are born into a nuclear family structure consisting of two parents and their children. Cheal (1993, p.13) argued that postmodern societies are characterized by choice so that individuals have the freedom to determine the type of family and personal relationships they want. As a result, no one family type dominates. There can be a single-parent family, a diverse-extended family, and others. Each family might also have a different kind of role division among family members, unlike the modern nuclear family with a more apparent division.

In the Darling family, the mother is the only adult in the family; hence she becomes the head of the family, responsible for working and taking care of her children. Because they are growing up in a lower-class family, the children are also given a responsibility to help their mother running the family diner since they are very 
young. A scene shows a 10-year-old Wendy working as the waitress, serving food to customers and cleaning the tables (Zeitlin, 2020, 08:35 - 09:00). In another scene, while Wendy is looking for turtles and running following the passing train, her mother calls out for her hand with the dishwashing (Zeitlin, 2020, 15:00 15:30). The same applies to James and Douglas. Whenever they play and have fun, immediately the mother tells them to stop playing around and start working, "Both of you, now! Let's go! You've gotta get to work. I've been waiting here forever" (Zeitlin, 2020, 09:20 - 09:55). The mother is portrayed expecting her children to take responsibility in the family business.

The examples show that the film challenges Ariès' (1960) modern Western conception of childhood, which believes that children's only role and responsibility is to get an education and nurture in preparation for adulthood (Mook, 2007, p.141). In this dominant western view, they are considered innocent and therefore excluded or separated from adults' life. However, this childhood concept is considered limited only to children from specific backgrounds. Children from different races, nationalities and social classes might have different experiences. Other than going to school and playing around, the Darling's children have to work due to their family's impoverished condition. By giving them a share of responsibilities, Wendy's mother views her children as competent and capable individuals who can support the family. This perception indicates that society's perception towards what children should or should not do in their childhood varies and relates to their social class. For a lowincome family coming from the lower class society, just how it is shown in Wendy (2020), there is a need for the parents to see their children as the workforce who can help them maintain the family survival. Childhood experience from the working class is different from the middle-class childhood in Peter Pan (1904).

\section{Children's Agency}

In this film, the children's agency can be seen through their act of resistance conforming to the structural condition surrounding them. For instance, in the opening scene of this movie, there is a birthday party held in the Darlings' diner and, the people there are having a conversation about the children's future (Zeitlin, 2020, 03:26 - 04:16).

Customer A: Maybe they gonna be politicians.

Customer B: Dream on, Potts.

Old lady: When these kids grow up, they will be running this place. One day, these little munchkins are gonna be moppin' after us. Douglas, you could be the waiter, and James, you could be the cashier.

James and Douglas: No, no

Thomas: Grandma, I could be a pirate?

Old lady: Pirate? We're not hiring for a pirate. You're gonna be a mop and broom man.

Thomas: I ain't gonna be a mop and broom man. Old lady: Nobody wants to be a mop and broom man, but that's damn true how we end up. You think Goose wants to be a toilet scrubber when he was eight?

The conversation captures the structural issue that is going on in that society, where for the lower class people, it is hard to escape the dominant structure that already lasts for a long time. The children are expected to end up working in that diner again when they grow up. However, the children reject that idea. Thomas, the birthday boy, even states his disagreement to be a mop and broom man twice with a grey face. After that, the next thing he does is escaping the diner and going away somewhere with the passing train. This act of resistance can be counted as his agency as a child to disagree with the existing structure and want to be free from it. It challenges the modern childhood's function, which is to be prepared to fit and contribute to an ordered, balanced society (Meynert, 2013, p.103).

\section{Child-Adult Relationship}

Previously, the modernists view childhood and adulthood as binary oppositions. Childhood is seen as a completely different stage from adulthood, locating children and adults in dichotomous hierarchical relationships. This perception limits children's interactions with unrelated adults and their exposure to problems and issues considered to be beyond their age. Benedict (as cited in Thorne, 2009) observed how in the 1930s, the U.S. culture emphasized the child-adult dualisms.

The child, Benedict noted, "must be protected from the ugly facts of life," including sexuality (notions of innocence infuse the modern idea of "the child"), while the adult must encounter these facts "without psychic catastrophe;" "the child must obey, the adult must command this obedience;" the child is framed as irresponsible, the adult defined by responsibility. (p. 20)

Meanwhile, in the postmodern perspective of childhood, the distinction between childhood and adulthood becomes obscured as children are getting more exposed to adults' world and social issues that previously are concealed from children. As a result, many children now share commonalities with adults in terms of their struggles and responsibilities. In Wendy 
(2020), the Darling children have to bear the responsibility to earn a living along with their mother since they were little. They have also been accustomed to meet and interact with unrelated adults who come to their mother's diner as customers since they are very young, which exposes them even more to the adult world. Furthermore, the way parents and children interact in some families shift to be more casual and intimate. For instance, in a scene when the children ask their mother to tell them a story, James says, "Tell us a story, woman." Their mother then answers, "I can't. I have to work, dudes" (Zeitlin, 2020, 10:19 - 10:23). The use of the words 'woman' and 'dudes' in the conversation to call each other signifies the casual relationship between a mother and a child, which often occurs in the working class society.

The dynamic of the child-adult relationship in postmodern childhood is also shown through a scene on the mysterious island. One day, Wendy finally discovered the abandoned part of the island destroyed by the volcanic eruption years ago. Now that location is a home for older people who look miserable and depressed. Looking at their condition and the destruction that happens in the environment, Wendy wants to take the initiative to help them. In an abandoned bar, she asks in a clear and assertive tone, "Does anyone know how to stop this?" which gets no answer. She then continues by giving them advice, "You won't be so miserable if you just talk to each other." (Zeitlin, 2020, 01:04:14 - 01:04:30). When she talks, the camera shoots her firm facial expression through a medium close-up shot, making her look more powerful. Meanwhile, the older people's facial expression shows that they are hopeless and feeling depressed with their condition. After that, Wendy pretends to make a drink for an older man to make him feel better, just like what she usually does in the diner. She says, "I'm making you a blueberry cocktail with a pinch of margarita. There you go, darling." (Zeitlin, 2020, 01:04:45 - 01:04:55).

This scene distorts the generalization view of children as incompetent individuals while adults are seen as more competent. Instead, it highlights the adults' inability and incompetency to solve their problems and therefore need to be cared for by others. Thus, as a child, Wendy has to be the one who steps up, takes the initiative by herself, and even advises the adults. It reflects the idea of children become 'adultified,' and adults become 'childified' (Aronowitz and Giroux; Best and Kellner as cited in Kincheloe, 2011, p.281). Due to the circumstances, sometimes children become more mature and wise like the grown-ups, especially when they find that adults surrounding them are incompetent and think they can do something better.
Furthermore, this film debunks the message being delivered in the original work regarding the idea of growing up and becoming adults. Peter Pan (1911) views childhood and adulthood as two separate phases that do not share any commonalities. Childhood in that novel is identical to a phase full of happiness, imagination, and adventures, while adulthood is viewed as a terrible thing. Once children grow up, become adults, and are exposed to many problems, they will not have dreams or adventures that they once had anymore. As Turner (2018, p.14) states, in Peter Pan (1911), "adulthood, manhood, means accepting reality and leaving behind the fun adventures of childish play enabled by creativity and imagination only innocence is capable of stimulating."

At the end of the story, Wendy grows up and becomes a mother of a daughter named Jane. When Jane asks Wendy why she could not fly anymore and go to Neverland, she says that "Because I am grown up, dearest. When people grow up, they forget the way". Jane then asks why grown-up people forget their way, which is answered by Wendy saying that "Because they are no longer gay and innocent and heartless. It is only the gay and innocent and heartless who can fly." (Barrie, p.236). In this story, the children can fly and go to Neverland because they use their imagination. Thus, this conversation indicates how imagination is an exclusive quality of childhood. Once a child grows up into an adult, their maturity prevents them from exercising their imagination the way they used to be. When the Lost Boys finally grow up, and each of them is either getting married or having a job, none of them remember their lives in Neverland. "...You see that judge in a wig coming out at the iron door? That used to be Tootles. The bearded man who doesn't know any story to tell his children was once John..." (Barrie, p.234). The words 'used to' and 'once' emphasizes the distinction between children and adults. It gives an impression that once the children grow up and leave their childhood behind, they would be totally different.

In Wendy (2020), the Peter Pan syndrome marked with a resistance to grow up is also why the children escape from their home and go to the island in the beginning. Wendy does not want to grow up because she is afraid that she has to give up on her childhood dream, just like her mother. Wendy's mother once had a dream to do rodeo, but this dream was changed once she became a mother and had children. Thomas does not want to grow up and be a mop and broom as expected by society. This view changes by the end of the film when Wendy finally realizes that growing up and becoming an adult is a thing that will undoubtedly happen, and it is impossible to escape. However, the film tries to break free from Barrie's strict boundaries between 
childhood and adulthood. The grown-up Wendy believes that adults can also have adventures in the same manner as children. She says to Peter Pan and the others, "Our lives are gonna be the greatest story ever told. And the bigger we get, the huger our stories will be. We will explore the earth and mend the planet." (Zeitlin, 2020, 01:33:02 - 01:33:16). This idea is approved by both the children and the older people. The unity between the children and the older people is portrayed as the power needed to save Mother. So, when they chant together, the mission to save Mother is accomplished.

Finally, this film is closed with footage showing the Darling children and the Lost Boys are already returning home and celebrating happy moments, like birthday parties and weddings together from year to year. As the footage is shown, there is Wendy's voice narrating,

"Peter promised he would visit as soon as he could, so we waited and counted the days. Time went by and moved faster and faster. We tried to remember every adventure for him, but there were too many to tell them all. There were miracles, and there were tragedies and journeys beyond our wildest dreams. We would travel to many corners of the earth and find that there's magic everywhere, and not just in Peter's island" (Zeitlin, 2020, 01:40:56 - 01:42:40).

The footage and narration imply that even though all children will eventually grow up, they will still always cherish things like having their own adventures and dreams. From these examples, it can be seen that in the end, the dynamic of childhood and adulthood in this film becomes more fluid and flexible. Childhood is not portrayed as a phase filled with happy things anymore, and entering adulthood does not necessarily mean a curse or a trap because adults can still retain the ability to have dreams and imagination.

\section{CONCLUSION}

To sum it up, even though both works explore the theme of childhood, the kind of childhood presented in Wendy (2020) is not the same as the one in Peter Pan novel (1911). Instead of glorifying childhood and putting children as objects of adult desires to fulfil their sense of nostalgia for a lost childhood, the film focuses on capturing the childhood experience from the children's perspective. Wendy (2020) highlights the childhood experienced by children from a lower-class family which also captures the concept of postmodern childhood by depicting the children's roles, child-adult relationships, and the children's agency. The presence of the postmodern childhood construction in Wendy
(2020) is essential as it is appeared to be more suitable and relevant for today's audience.

Moreover, it is also used as a critic of the modern construction that totally separates childhood from adulthood. In Wendy (2020), the conception of modern childhood that children are purely innocent and incomplete human beings who need to be protected and prepared for entering society is no longer retained. Due to their family social background and impoverished condition, the Darling children must take up some of the adult's roles since they were little. This portrayal also indicates that the binary opposition and dichotomous hierarchical relationship between children and adults have become more fluid in postmodern childhood. Children in the film have to deal with the same struggles and responsibilities as adults, which makes them appear to be less innocent and more mature. Furthermore, the children in the film are portrayed as vocal in performing their agencies and free will through their resistance against the prescribed roles designated to them by society.

The adaptation of the film Wendy (2020) from Peter Pan from the early $20^{\text {th }}$ century proves that childhood as a social construct remains to change and vary. Wendy itself highlights the contrast between childhood experiences from low-income families in the 21st century with the concept of modern childhood shown in the novel from the early $20^{\text {th }}$ century. The way childhood is experienced by children and perceived by society differs across times, locations, cultures, and social backgrounds. A ten-year-old child's responsibility might be only studying in one society and becoming the head of a family in another. Thus, postmodernist perspective embraces this plurality of childhood instead of accepting the idea that there is a universal concept of childhood that is suitable for every child.

\section{REFERENCES}

Barrie, J.M. (1994). Peter Pan. London, UK: Puffin Books. (Original work published 1911).

Bignell, J. (2005). Familiar aliens: Teletubbies and postmodern childhood. Screen, 46(3), 378-388. https://doi.org/10.1093/screen/46.3.373

Bordwell, D \& Thompson, K. (2008). Film art: An introduction (8th ed.). New York: McGraw-Hill.

Chappell, D. (2008). Sneaking out after dark: Resistance, agency, and the postmodern child in JK Rowling's Harry Potter series. Children's Literature in Education, 39, 281-293. https://doi.org/ 10.1007/s10583-007-9060-6

Cheal, D. (1993). Unity and difference in postmodern families. Journal of Family Issues, 14(1), 5-19. https://doi.org/10.1177/0192513X93014001002 
Edelstein, D. (2020, February 27). Wendy takes a children's classic into art-house neverland. Vulture. https://www.vulture.com/2020/02/ wendy-benh-zeitlin-movie-review.html

Franklin, M. (2012). "Second to the right and straight on till morning": The construction and distortion offantasy In J.M. Barrie's Peter Pan [Bachelor's thesis, Haverford College]. Institutional Scholarship. https://scholarship.tricolib.brynmawr.edu/ handle/10066/8264

Hicks, L. (2020, February 29). The wilderness of 'Wendy': A conversation with Benh Zeitlin. Film School Rejects. https://filmschoolrejects.com/ benh-zeitlin-wendy/

Hutcheon, L. (2012). A theory of adaptation (2nd ed). New York: Routledge.

Ilustrations by F.D. Bedford. (n.d.). Mapping neverland. http://www.ericrettberg.com/peterpan/ ?page_id=166

Jenks, C. (2005). Childhood (2nd ed.) London: Routledge.

Kincheloe, J. (2011). Home alone and "bad to the bone": The advent of a postmodern childhood. In S.R. Steinberg (Eds). Kinderculture: The corporate construction of childhood. New York: Routledge. https://doi.org/10.4324/9780429495090

Le Roux, S.R. (2016). The Peter Pan story in the literary and cultural imagination: Exploring the many re-imaginings of J.M. Barrie's Story [Master's thesis, North-West University] NWU Institutional Repository. https://repository.nwu. ac.za/handle/10394/21085

Livingston, G. (2018, April 27). About one-third of U.S. children are living with an unmarried parent. Pew Research Center. https://www.pewresearch.org/fact-tank/2018/04/27/about-onethird-of-u-s-children-are-living-with-anunmarried-parent/

Loo, H. (2012). Children in Postmodern Literature: A Reconstruction of Childhood. Hohonu: A Journal for Academic Writing, 10, 59-61.

McCallum, R. (2018). Screen adaptations and the politics of childhood: Transforming children's literature into film. London: Palgrave Macmillan. https://doi.org/10.1057/978-1-137-39541-2

Meynert, M. (2013). Conceptualizations of childhood, pedagogy and educational research in the postmodern: A critical interpretation [Master's thesis, Lund University]. Lund University Publication. https://lup.lub.lu.se/record/4438099

Mook, B. (2007). The Changing nature of childhood: A metabletic study. Collection du Cirp, 1, 137159.

Thorne, B. (2009). "Childhood": Changing and dissonant meanings. International Journal of Learning and Media, 1(1), 19-27. https://doi.org/ 10.1162/ijlm.2009.00010

Turner, C. (2018). Leaving Neverland for Narnia: Childhood and gender in Peter Pan, The Secret Garden, and The Lion, The Witch and The Wardrobe [Master's thesis, Georgia College]. Knowledge Box: Georgia College Repository. https://kb.gcsu.edu/english/2

Yoo, H. (2019). Imperialism and the politics of childhood innocence in Peter Pan and Wendy. The Lion and the Unicorn, 43(3), 387-405. https://doi.org/10.1353/uni.2019.0042

Zeitlin, B. (Director). (2020). Wendy [Film]. TSG Entertainment 